\title{
Does spirituality mediate the relationship between environmental stressors and psychological well-being in distressed unemployed people?
}

\author{
Authors: $\quad$ Juanita Muller ${ }^{1}$ \\ Peter Creed ${ }^{2}$ \\ Laurie Francis ${ }^{1}$ \\ 1 Griffith University, School of Applied Psychology and Centre for Work, Leisure and Community \\ Research \\ 2 Griffith University, School of Applied Psychology and Service Industry Research Centre
}

Correspondence:

Dr Juanita Muller

Centre for Work, Leisure \& Community Research

Logan campus, Griffith University

University Drive, Meadowbrook

Queensland 4131, Australia 


\title{
Does spirituality mediate the relationship between environmental stressors and psychological well-being in distressed unemployed people?
}

\begin{abstract}
A sample of 231 unemployed adults was surveyed using scales tapping psychological distress, the latent and manifest benefits of employment and spirituality (connectedness, universality, prayer fulfillment, attendance at worship). It was hypothesized that the latent and manifest benefits would be associated with well-being, spirituality would be associated with well-being, spirituality would be associated with the latent and manifest benefits, and spirituality would mediate the relationship between the latent and manifest benefits and psychological distress. The latent and manifest benefits were associated with psychological well-being in the expected direction, with the strongest associations being between well-being and financial deprivation, social support and time structure. One spirituality dimension, prayer fulfillment, was positively associated with well-being, and those reporting higher spirituality also reported greater access to the latent, but not manifest, benefits. Last, spirituality mediated the relationship between the latent benefits of employment (social support and collective purpose) and well-being. Results are discussed in the context of the latent deprivation and agency restriction theories of well-being and unemployment. Practical implications are highlighted.
\end{abstract}




\section{Does spirituality mediate the relationship between environmental stressors and psychological}

\section{well-being in distressed unemployed people?}

Unemployment rates in Australia increased from 88,000 in August 1982 to record levels of 963,200 in August 1993 (Australian Bureau of Statistics, 1993), but have tapered off to the present level of just over 600,000 people out of work, or $6 \%$ of the workforce (Australian Bureau of Statistics, 2003). During this decade, however, there have been changes in the definition and legislation regarding full-time employment, and the reduction may reflect some of these changes rather than this being an actual decrease in the number of people unemployed. These statistics represent a large number of Australians whose lives are adversely affected by being deprived of the means to earn a living and, in many cases, the opportunity to experience a full life. According to researchers, the nature of unemployment facilitates experiences that undermine the person's selfesteem, prospects for the future and ultimately the person's sense of well-being (Fryer, 1986; Haworth, 1997; Jahoda, 1982).

Two prominent theories that have made significant contributions to understanding this decline in well-being as a result of unemployment are the latent deprivation model (Jahoda, 1982, 1984) and the agency restriction model (Fryer, 1986; Fryer \& Payne, 1984). Jahoda viewed employment as the means of gaining access to both the manifest benefits (associated with income) and latent benefits (associated with meeting psychological needs) of paid work. She theorized that people primarily engaged in paid work to attain manifest benefits, but whilst employed profited from five main categories of psychological experience related to innate human needs for structured time, social contact, collective purpose, personal identity and activity. When access to these latent benefits is severed by unemployment, the deprivation contributes to a decline in mental health.

Fryer (1986; Fryer \& Payne, 1984) has criticized the latent deprivation model by suggesting that Jahoda placed too great an emphasis on the role of social factors, and too little emphasis on 
personal agency and its restriction by the financial deprivation associated with unemployment. Fryer considered that the main negative consequence of unemployment was the loss of the manifest benefits (loss of income) rather than the loss of the latent benefits, as argued by Jahoda. Financial gains facilitate the acquisition of necessities for daily living and give the person the opportunity to plan a meaningful future. When this personal agency is restricted by relative and absolute poverty and economic insecurity due to unemployment the result is a decline in psychological well-being.

Both theories acknowledge the importance of the manifest and latent benefits gained from work and their relationship with well-being, although there is disagreement as to which benefits are the more influential in predicting well-being. Recent researchers (Creed \& Macintyre, 2001; Waters \& Muller, 2003) have treated the two theories as complimentary, rather than in competition. By examining the combined effects of these experiences it is possible to gain a more complete understanding of the relative importance of each benefit, their relationship with each other and their relationship with well-being.

One of Jahoda's main hypotheses was that the latent benefits are mainly derived from paid employment. Fryer has disputed this, suggesting that the latent benefits can be obtained away from paid work, but due to financial constraints, the unemployed find it difficult to access them from other avenues. The current study proposes to test the capacity of spiritual organization as an alternative to paid employment, as it is a prime candidate to offer latent benefits. The experiences of work and the experiences of spiritual belongingness are both likely to provide similar latent benefits. Both are "collectives" with hierarchies of power (Weber, 1924; cited in Pugh 1997) dedicated to achieving a particular mission, although one is for profit (work) and the other is notfor-profit (spiritual organization; Wood, Wallace, Zeffane, Schermerhorn, Hunt, \& Osborn, 1998). Both provide the benefits of time structure (to attain organizational and personal goals), social contact (activities with co-workers/members), of having a collective purpose (a sense of unity with others), personal identity (as worker/relationship with spiritual other) and structured activities (job 
tasks/serving others). In other words, it is argued that spiritual belongingness provides a social structure and access to the latent benefits that were previously only attributed to paid employment. Under these circumstances, it is expected that access to the latent benefits will improve psychological well-being.

Past research involving religion and spirituality has suffered from an inability to operationally define both religion and spirituality. The term "religion" has traditionally been used as a broad term referring to an institutionalized form of faith, whereas its modern-day counterpart of "spirituality" has usually been used in a more personalized context (Slater, Hall, \& Edwards, 2001). In the present study we tap both constructs but use the term spirituality to refer to both religion and spirituality.

A summary of findings from previous research on spirituality that is relevant to the current study indicates that traditional conceptions of spirituality, such as a belief in a higher power, prayer and attendance at worship, are associated with higher levels of well-being (Francis \& Kaldor, 2002). Attendance at worship has been shown to be positively associated with well-being and negatively related to distress (Ellison, Boardman, Williams \& Jackson, 2001). Further, religious beliefs have been found to be associated with lower levels of depression and hopelessness (Murphy et al., 2000), and spiritual well-being has been found to be negatively correlated with both stress (Ellison \& Smith, 1991) and depression (Fehring, Brennan \& Keller, 1987).

A focus on the benefits of employment, spirituality and psychological well-being has previously not been included in unemployment research. The unemployment studies reviewed above indicate support for a direct effect of financial deprivation and the loss of the latent benefits of employment on reducing psychological well-being. The spirituality studies indicate a direct effect of spirituality on improving well-being. It is also likely that spirituality will not only influence well-being directly, but will have an influence by reducing the effects of the loss of the latent benefits of employment. This latter case refers to spirituality mediating the effects of the latent benefits of employment on Council for Educational Research. Copyright 2004 Australian Council for Educational Research. 
well-being. It is hypothesised that this will happen because the individual is associated with a social institution other than work that allows access to the latent benefits, and because such an association allows the unemployed person to adopt a more future orientated view of their circumstances. From this latter perspective, spiritual beliefs can be seen as a style of cognitive coping that may protect against the adverse effects of stress and deprivation caused by unemployment. Research in this area has shown that several factors, such as designating oneself as "born-again", believing in a god as a causal agent, and making a spiritual commitment, have been found to be associated with an increased sense of spiritual well-being and an overall sense of psychological well-being (Ellison \& Smith, 1991).

In light of these results, it is possible to conclude that spirituality assists individuals to cope better with life disruptions and allows them to view life more positively. Additionally, it is possible to argue that the spiritual institutions and belongingness that form the social support system will provide access to latent benefits and therefore enhance psychological well-being. The aim of the current study, then, is to investigate links between spirituality, the latent benefits of employment, financial deprivation and psychological well-being in unemployed persons. The spirituality measures used are prayer fulfillment, universality, connectedness, and attendance at worship. The following hypotheses are proposed:

1. The latent and manifest benefits of employment will be associated with well-being, with those having less access to the latent benefits and more financial deprivation reporting more psychological distress;

2. Spirituality will be associated with well-being, with those higher on spirituality reporting less psychological distress;

3. Spirituality will be associated with the latent and manifest benefits of employment, with those higher on spirituality more likely to have better access to the latent benefits and perceive lower financial deprivation; 
4. Spirituality will mediate the relationship between the latent and manifest benefits of employment and psychological distress.

\section{Method}

\section{Participants}

A total of 248 unemployed adults were surveyed. A list-wise deletion procedure indicated that 17 participants did not adequately complete all components of the survey. This left 231 in the sample, which comprised 127 (55\%) females and 104 (45\%) males, who had a mean age of 30.71 years (SD $=11.47)$ and who had been unemployed on average for 1.80 years $(S D=3.15)$.

\section{Measures}

Psychological Distress. Well-being was operationalised as the 12 -item version of the General Health Questionnaire (Goldberg, 1972), which provides a global measure of psychological distress. This version has been recommended by Banks et al. (1980) for use in occupational studies, and has been used extensively by researchers in this area (Creed \& Macintyre, 2001). Respondents indicated on a four-point response format how they have felt recently in a number of areas, including cognitive processing, self-esteem, anxiety and depression (e.g., "Have you recently been losing confidence in yourself?”). Higher scores indicate more psychological distress. Creed and Macintyre reported an internal reliability coefficient of .89 with an unemployed sample; the coefficient for the current sample was .92 .

Latent Benefits of Employment. Five 6-item subscales from the Latent and Manifest Benefits scale (Muller, Creed, Waters \& Machin, 2000) were used to measure the latent benefits of Time Structure, Social Support, Collective Purpose, Status and Activity. Participants indicated the strength of their agreement to bipolar statements using a 7-point response format. Sample items were "Time usually drags for me/Time rarely drags for me" (Time Structure), "I regularly do things 
with other people/I rarely do things with other people" (Social Support), "I usually feel a part of the community/I rarely feel a part of the community" (Collective Purpose), "What I do is important/What I do is not important" (Status), and "I usually have a lot of things to do/I rarely have a lot of things to do" (Activity). Higher scores indicate more access to the latent benefits. Muller et al. reported satisfactory psychometric properties for the scale. The internal reliability coefficients for the present sample were .87 (Time Structure), .92 (Social Support), .90 (Collective Purpose), .91 (Status), and .88 (Activity).

Manifest Benefits of Employment. The 6-item Financial Deprivation subscale from the Latent and Manifest Benefits scale (Muller et al., 2000) was used to measure the manifest benefit of employment. Respondents indicated their strength of agreement to bipolar statements, such as, "I can usually live on the money I receive/I usually have trouble living on the money I receive". Higher scores indicate more Financial Deprivation. The internal reliability coefficient for the subscale with this sample was .91 .

Spirituality. The 24-item Spiritual Transcendence Scale (Piedmont, 1999) was used to assess three related themes of Prayer Fulfillment, Universality and Connectedness. The 9-item Prayer Fulfillment subscale provides a measure of belief in personal prayer (e.g., "I find inner strength and/or peace from my prayers or meditations"); the 9-item Universality subscale taps meaning and purpose of life ("I believe that there is a larger plan to life"); and the 6-item Connectedness subscale taps a sense of community and relationship with others, past, present and future (e.g., "I am concerned about those who will come after me in life"). Participants responded to all items using a 5-item response format. Higher scores indicate more Prayer Fulfillment, Universality and Connectedness, respectively. Slater et al. (2001), in their review of religion and spirituality measures, reported that the Spiritual Transcendence Scale appeared to capture the three concepts in the corresponding subscales. Piedmont (1999) reported internal reliability coefficients for the Council for Educational Research. Copyright 2004 Australian Council for Educational Research. 
subscales of $.97, .97$ and .94 , respectively; the corresponding coefficients for the present sample were $.94, .94$ and .76 .

Biographic. Participants were asked to indicate their age, gender, length of unemployment, and regularity of attendance at worship. Attendance at Worship was measured with the single item, "How often do you participate in church or other corporate spiritual practice?" (Francis \& Kaldor, 2002), using an 8-point response format ("more than once a week" to "never"). Scores on this item ranged from 1-8, with higher scores indicating more regular attendance.

\section{Procedure}

The study was cross-sectional, and involved administering surveys to unemployed participants who utilized the national employment agency in metropolitan southeastern Queensland.

\section{Results}

\section{Validity of Study Measures}

To test the construct validity and independence of the scales used in the study, the 78 items from the General Health Questionnaire (12 items), the Latent and Manifest Benefits subscales of Time Structure (6), Social Support (6), Collective Purpose (6), Status (6), Activity (6), and Financial Deprivation (6), and the three spirituality subscales of Prayer Fulfillment (9), Universality (9) and Connectedness (6) were included in a principal axis factor analysis, using a direct oblimin rotation. The Kaiser-Meyer-Olkin Measure of Sampling Adequacy (.85) and Bartlett's Test of Sphericity ( $p$ $<.001$ ) indicated the suitability of the data for factor analysis (Tabachnik \& Fidell, 1996). Initially, 12 factors were indicated based on the criterion of eigenvalues being greater than one. However, this solution was factorially complex and difficult to interpret. When ten factors were rotated, to reflect the number of scales included in the analysis, ten interpretable factors emerged. All items loaded on their respective factors, and there were only three cross-loadings $(>.30)$, where three 
Connectedness items also loaded on the Universality subscale. This solution accounted for $67.35 \%$ of the variance and demonstrated the independence of the scales. Given this result, all 78 items were retained and subscale totals were calculated based on the original number of items in each scale. Summary data and bivariate correlations among all variables based on these factor analyses are reported in Table 1. 
Table 1

Summary data for Psychological Distress, Time Structure, Social Support, Collective Purpose, Activity, Status, Financial Deprivation, Prayer Fulfillment, Universality, Connectedness, Attendance at Worship, Age, Gender and Length of Unemployment

\begin{tabular}{|c|c|c|c|c|c|c|c|c|c|c|c|c|c|c|c|c|c|}
\hline Variable & $n$ & $M$ & $S D$ & 1 & 2 & 3 & 4 & 5 & 6 & 7 & 8 & 9 & 10 & 11 & 12 & 13 & 14 \\
\hline 1. Psychological Distress & 231 & 14.78 & 7.78 & - & $-.21 * *$ & $-.35 * * *$ & $-.31 * * *$ & $-.19 * *$ & $-.15 *$ & $.37 * * *$ & $-.20 * *$ & -.01 & .10 & $-.15^{*}$ & .06 & $.17 * *$ & .09 \\
\hline 2. Time Structure & 231 & 27.47 & 9.22 & & - & .13 & $.24 * * *$ & $.36 * * *$ & $.32 * * *$ & -.01 & .03 & .05 & .02 & .06 & $-.16^{*}$ & .08 & .07 \\
\hline 3. Social Support & 231 & 25.99 & 9.98 & & & - & $.49 * * *$ & $.17 * *$ & $.36 * * *$ & $-.29 * * *$ & $.15^{*}$ & .09 & -.12 & .09 & $-.15^{*}$ & $-.16^{*}$ & -.05 \\
\hline 4. Collective Purpose & 231 & 23.09 & 9.56 & & & & - & $.28 * * *$ & $.28 * * *$ & $-.36 * * *$ & $.27 * * *$ & $.17 *$ & $.13^{*}$ & $.25 * * *$ & -.07 & .06 & -.06 \\
\hline 5. Activity & 231 & 29.79 & 8.42 & & & & & - & $.61 * * *$ & .03 & .11 & $.15^{*}$ & .05 & .06 & $-.14 *$ & -.01 & .11 \\
\hline 6. Status & 231 & 32.22 & 8.64 & & & & & & - & .11 & .10 & $.18 * *$ & .01 & -.01 & $-.22 * *$ & $-.16^{*}$ & .13 \\
\hline 7. Financial Deprivation & 231 & 31.33 & 9.61 & & & & & & & - & -.09 & .01 & .06 & -.09 & $.23 * * *$ & $.20 * *$ & .03 \\
\hline 8. Prayer Fulfillment & 231 & 2140 & 10.99 & & & & & & & & - & $.58 * * *$ & $.29 * * *$ & $.64 * * *$ & .08 & .07 & .02 \\
\hline 9. Universality & 231 & 30.37 & 10.50 & & & & & & & & & - & $.58 * * *$ & $.34 * * *$ & -.05 & .05 & $.19 * *$ \\
\hline 10. Connectedness & 231 & 18.50 & 5.88 & & & & & & & & & & - & $.17 * *$ & .05 & $.17 * *$ & .12 \\
\hline 11. Attendance at Worship & 231 & 2.91 & 2.56 & & & & & & & & & & & - & .06 & $.15^{*}$ & .02 \\
\hline 12. Length of Unemployment ${ }^{\mathrm{a}}$ & 227 & -.18 & .60 & & & & & & & & & & & & - & $.15^{*}$ & -.10 \\
\hline 13. Age & 231 & 30.71 & 11.47 & & & & & & & & & & & & & - & -.02 \\
\hline 14. Gender & & & & & & & & & & & & & & & & & - \\
\hline
\end{tabular}

Note. ${ }^{a}$ Length of Unemployment was Log10 transformed to meet normality assumptions. $*=p<.05, * *=p<.01, * * *=p<.001$.

Effects of Spirituality and the Latent and Manifest Benefits on Psychological Distress 
A standard regression analysis was used to test for the effects of spirituality and the latent and manifest benefits of employment in contributing to the prediction of Psychological Distress. In this analysis, Psychological Distress was used as the dependent variable. The independent variables included were Time Structure, Social Support, Collective Purpose, Activity, Status, Financial Deprivation, Prayer Fulfillment, Universality, Connectedness and Attendance at Worship. The demographic variables of Age, Gender and Length of Unemployment were also included as independent variables. All variables together were able to significantly predict Psychological Distress, $F(13,213)=6.73, p<.001$, and account for $29.1 \%$ of the variance. The variables to make significant individual contributions were, in order of importance, Financial Deprivation (4.41\%), Social Support (2.53\%), Time Structure (2.19\%) and Prayer Fulfillment (1.49\%). Summary data for this regression analysis are reported in Table 2.

Table 2

Summary data for standard regression analysis for Time Structure, Social Support, Collective Purpose, Activity, Status, Financial Deprivation, Prayer Fulfillment, Universality, Connectedness, Attendance at Worship, Age, Gender and Length of Unemployment predicting Psychological Distress $(N=227)$

\begin{tabular}{|c|c|c|c|c|}
\hline Variable & $B$ & $S E B$ & C & $\begin{array}{c}\text { Partial } \\
\text { Correlation }\end{array}$ \\
\hline Time Structure & -.14 & .05 & $-.16^{*}$ & -.15 \\
\hline Social Support & -.16 & .06 & $-.21 * *$ & -.16 \\
\hline Collective Purpose & -.01 & .06 & -.01 & -.01 \\
\hline Activity & -.11 & .07 & -.12 & -.09 \\
\hline Status & .01 & .08 & .01 & .01 \\
\hline Financial Deprivation & .21 & .06 & $.25 * * *$ & .21 \\
\hline Prayer Fulfillment & -.13 & .06 & $.19^{*}$ & -.12 \\
\hline Universality & .06 & .06 & .07 & .05 \\
\hline Connectedness & .07 & .10 & .05 & .04 \\
\hline Attendance at Worship & -.07 & .23 & -.02 & -.02 \\
\hline Age & .08 & .04 & .11 & .10 \\
\hline Length of Unemployment & -.28 & .19 & -.09 & -.08 \\
\hline Gender & 1.39 & .94 & .09 & .09 \\
\hline
\end{tabular}


Structural equation modeling (AMOS: Arbuckle \& Wothke, 1995) was employed to test whether spirituality acted as a mediating variable between the effects of the loss of the latent and manifest benefits of employment and well-being. Structural equation modeling allows for the examination of a number of dependent relationships simultaneously (Tabachnick \& Fidell, 1996). This was required to allow spirituality (consisting of a composite of Prayer Fulfillment, Universality, Connectedness and Attendance at Worship) to be modeled as both a dependent (being predicted by the latent and manifest benefits) and an independent variable (predicting Psychological Distress). AMOS generates statistical measures of goodness-of-fit, the amount of variance explained by a model, and standardised regression coefficients to examine the effect of direct and indirect pathways. Six models were tested. The latent (Time Structure, Social Support, Collective Purpose, Activity, Status) and manifest benefits (Financial Deprivation) were modeled separately to determine the effect of spirituality as a mediator on each. Only two models met the criteria for mediation. The first model included Social Support as the initial variable, and the second model utilised Collective Purpose in this capacity. Standardised beta weights and squared multiple correlations for these models are reported in Figure 1. Each model produced a good fit to the data. For Social Support, the fit statistics were: $\chi^{2}(7)=15.52, p=.03 ; \mathrm{GFI}=.98 ; \mathrm{AGFI}=.94 ; \mathrm{IFI}=.98$; $\mathrm{NFI}=.96 ; \mathrm{TLI}=.95 ; \mathrm{CFI}=.98 ; \mathrm{RMSEA}=.07 ;$ and PCLOSE $=.19($ Byrne, 2001). For Collective Purpose, these were: $\chi^{2}(7)=12.73, p=.08 ; \mathrm{GFI}=.98 ; \mathrm{AGFI}=.95 ; \mathrm{IFI}=.98 ; \mathrm{NFI}=.97 ; \mathrm{TLI}=.97$; $\mathrm{CFI}=.98 ; \mathrm{RMSEA}=.06$; and PCLOSE $=.33$. Spirituality mediated the effects of Social Support and Collective Purpose on Psychological Distress. The indirect effects were $-.02(\beta=.14 \mathrm{x}-.15)$ for Social Support and $-.04(\beta=.27 \times-.13)$ for Collective Purpose. The other three latent benefits of employment, Time Structure, Activity and Status, and the manifest benefit of employment, Financial Deprivation, did not meet the criteria for mediation (Baron \& Kenny, 1986), as they did not significantly predict the latent variable of Spirituality (see Figure 1). 


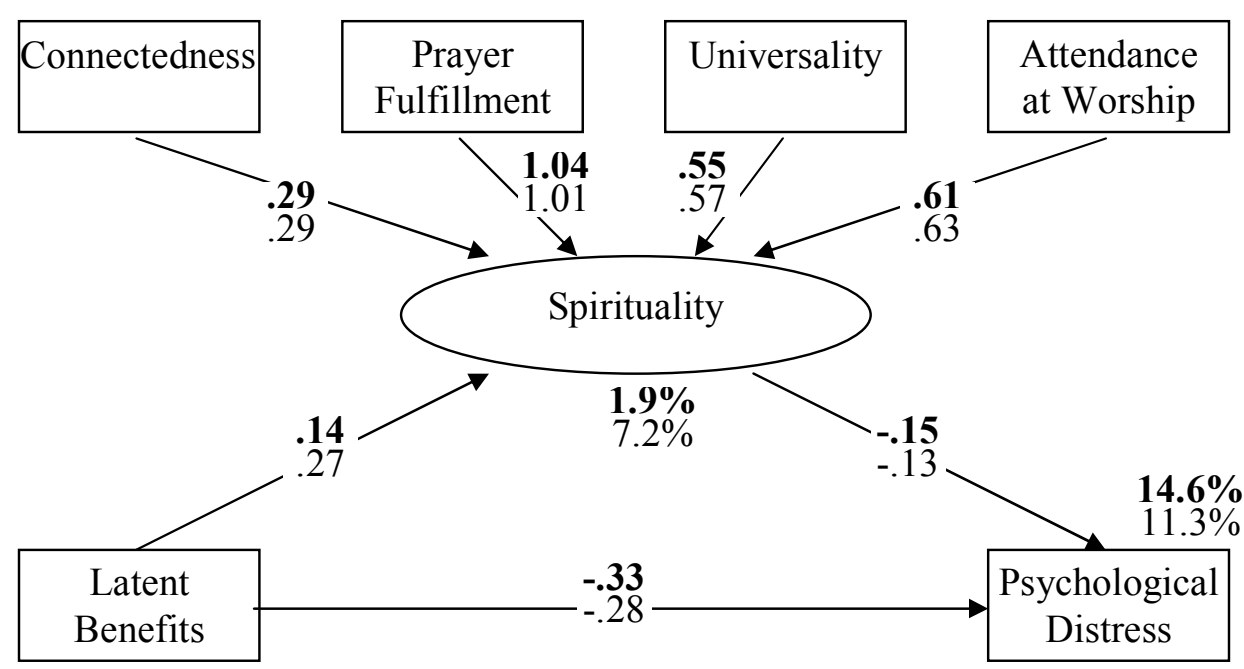

Figure 1. Model for Spirituality mediating the effects of the latent benefits of employment on Psychological Distress. Results for Social Support are reported in bold typeface; results for Collective Purpose are in non-bold typeface. Percentages are squared multiple correlations; numbers are standardised beta weights. All pathways are significant.

\section{Association between Spirituality and Latent and Manifest Benefits}

The bivariate correlations reported in Table 1 indicate small to moderate associations between some of the latent benefits of employment and spirituality, and no significant bivariate associations between the manifest benefits of employment and Spirituality. Specifically, Social Support was significantly associated with Prayer Fulfillment. Activity and Status were significantly associated with Universality, and Collective Purpose was significantly associated with Prayer Fulfillment, Universality, Connectedness and Attendance at Worship. Associations between the latent and manifest benefits of employment and the latent variable of Spirituality (see Figure 1) were consistent with these bivariate correlations, with only Collective Purpose and Social Support recording significant associations.

In summary, age, gender, length of unemployment, the latent and manifest benefits of employment, and the spirituality variables significantly predicted Psychological Distress in this sample of unemployed. Financial Deprivation, Social Support, Time Structure and Prayer Fulfillment made significant individual contributions. Spirituality did mediate the impact of the 
latent benefits of employment on Psychological Distress, although the effect was evident for only two variables, Social Support and Collective Purpose. Spirituality was significantly positively associated with two of the latent benefits, Social Support and Collective Purpose, but not associated with the manifest benefits of employment.

\section{Discussion}

The aim of this study was to examine the relationship between spirituality, the latent and manifest benefits of employment and psychological well-being in unemployed individuals. The rationale was to investigate whether spirituality would provide access to the latent benefits of employment that previous research suggested could only be gained from paid work, and whether spirituality would have a positive affect on well-being.

H1 was that the latent and manifest benefits of employment would be associated with well-being. Financial Deprivation and the two latent benefits of Time Structure and Social Support were significantly associated with Psychological Distress, with the largest association being found between Financial Deprivation and distress. These results are consistent with other studies. Financial Deprivation is typically found to be the variable most strongly associated well-being, with the latent benefits having weaker effects (e.g., Creed \& Macintyre, 2001; Waters \& Muller, 2003). Other studies have found different latent variables to be significantly associated with psychological distress. For example, Creed and Macintyre identified significant associations for Status, Time Structure and Collective Purpose, indicating that different unemployed samples record different losses of the latent benefits. Creed and Watson (2002) found latent benefit differences across different age groups, indicating that the impact of losing the latent benefits of employment are a function of other life variables.

H2 was that spirituality would be associated with well-being. This hypothesis was partially supported, with one of the spirituality variables, Prayer Fulfillment, or belief in personal prayer, the Australian Council for Educational Research. Copyright 2004 Australian Council for Educational Research. 
being significantly associated with distress, with a greater belief in personal prayer associated with better well-being. This was a weak direct effect compared to the effects of the latent and manifest benefits of employment, indicating a minor role for spirituality in psychological well-being in unemployed people. However, it is consistent with one of the findings of Francis and Kaldor (2002) that belief in prayer is associated with higher levels of well-being.

H3 proposed that spirituality would be associated with the latent and manifest benefits of employment. There was partial support for this hypothesis, with modest bivariate associations in the expected direction found between four of the five latent benefits and the spirituality measures. The strongest associations were found between Collective Purpose and spirituality, and no association was found for Activity. These modest associations were confirmed in the latent variable analyses, with Collective Purpose and Social Support recording significant associations with spirituality, indicating that unemployed people with high levels of spirituality also report more access to the latent benefits. It is not surprising that Collective Purpose and Social Support were the most significant latent benefits since they are also likely to be the most salient benefits associated with involvement in spiritual organisation. No association was found between the manifest benefit of Financial Deprivation and spirituality, indicating that spiritual beliefs may not operate as a cognitive coping style offering protection against the distress of unemployment as hypothesised.

H4 proposed that spirituality would mediate the relationship between the latent and manifest benefits of employment and psychological distress. Some support was found for this proposition, but this came from two of the latent benefits only, and no mediating relationship was found for Financial Deprivation. These results indicate that well-being is influenced by the latent benefits of employment (Social Support and Collective Purpose) and spirituality directly, and that well-being is also influenced by the latent benefits indirectly via spirituality, such that those with better access to the latent benefits have more of a spiritual outlook, which in turn is associated with better wellbeing. The evidence is that the latent benefits influence well-being directly and influence it 
indirectly by enhancing feelings of spirituality. This finding has implications for training and counselling for unemployed people. Providing unemployed people with the opportunity to be involved in organisations that provide them with a sense of collective purpose and social contact should assist in reducing the social isolation, lack of sense of purpose and other negative consequences of unemployment and may enhance feelings of belongingness. Government initiated interventions that may do so include "Work-for-the Dole" and other supported work schemes, as well as further education and training. Alternatively, from an individual counselling perspective, encouragement to become involved in other social, leisure or spiritual organisations is likely to provide individuals with such opportunities.

The study has a number of limitations, some of which have already been identified, such as the problem of operationalising spirituality. The main limitation is that the study has proposed causal relationships but has used cross-sectional methodology. While the notion that the spiritual organisation can provide an alternative social institution to work as an avenue for accessing latent benefits is an interesting proposition, longitudinal data are required to tease out the roles played by the latent and manifest benefits of employment and spirituality. Despite these shortcomings, there are some important findings from the study for unemployed people, including that: (1) access to latent and manifest benefits of employment is associated with positive psychological well-being; (2) reporting a spiritual orientation is associated with better well-being; (3) reporting higher spirituality is associated with better access to the latent benefits of employment; and (4) spirituality mediates the relationship of the latent benefits of employment and well-being.

These results are contrary to Jahoda's argument that only the social institution of work can provide access to these latent benefits, and thus maintain well-being. The results do, however, provide support for Fryer's views that the latent benefits of employment are less important to psychological well-being than the manifest benefits, and the latent benefits can be accessed from other avenues. The study also extends current research using these theoretical frameworks and 
supports the recent approach of treating the two theories as complimentary (Creed \& Macintyre, 2001; Waters \& Muller, 2003).

Final and authorised version first published in the Australian Journal of Career Development in 13 (2), published by the Australian Council for Educational Research. Copyright 2004 Australian Council for Educational Research. 


\section{References}

Arbuckle, J. L., \& Wothke, W. (1995). Amos 4.0 User's Guide. Chicago: Small Waters Corporation.

Australian Bureau of Statistics. 1993. Labor force, August, 1993. Canberra.

Australian Bureau of Statistics (2003). AusStats: 6202.0. Labour force, Australia. Canberra, ACT: Commonwealth of Australia.

Banks, M. H., Clegg, C. W., Jackson, P. R., Kemp, N. J., Stafford, E. .M., \& Wall, T. (1980). The use of the General Health Questionnaire as an indicator of mental health in occupational studies. Journal of Occupational Psychology, 53, 321-329.

Baron, R. M., \& Kenny, D. A. (1986). The moderator-mediator variable distinction in social psychological research: Conceptual, strategic, and statistical considerations. Journal of Personality and Social Psychology, 51, 1173-1182.

Byrne, B. (2001). Structural equation modeling with AMOS. London: Lawrence Erlbaum.

Creed, P., \& Macintyre, S. R. (2001). The relative effects of deprivation of the latent and manifest benefits of employment on well-being of unemployed people. Journal of Occupational Health Psychology, 6(4), 324-331.

Creed, P. A., Muller, J., \& Machin, M. A. (2001). The role of satisfaction with Occupational status, neuroticism, financial strain and categories of experience in predicting mental health in the unemployed. Personality and Individual Differences, 30, 435 - 477.

Creed, P. A., \& Watson, T. (2003). Age, gender, psychological well-being and the impact of losing the latent and manifest benefits of employment in unemployed people. Australian Journal of Psychology, 55, 95-103.

Ellison, C. G., Boardman, J. D., Williams, D. R., \& Jackson, J. S. (2001). Religious involvement, stress, and mental health: Findings from the 1995 Detroit area study. Social Forces, 80,1.

Final and authorised version first published in the Australian Journal of Career Development in 13 (2), published by the Australian Council for Educational Research. Copyright 2004 Australian Council for Educational Research. 
Ellison, C. W., \& Smith, J. (1991). Toward an integrative measure of health and well-being. Journal of Psychology and Theology, 19, 35-49.

Fehring,. R. J., Brennan, P. F., \& Keller, M. L. (1987). Psychological and spiritual well-being in college students. Research in Nursing and Health, 10, 391-398.

Francis, L. J., \& Kaldor, P. (2002). The relationship between psychological well-being and Christian faith and practice in an Australian population sample. Journal for the Scientific Study of Religion, 41, 1, 179-184.

Fryer, D. (1986). Employment deprivation and personal agency during employment. Social Behaviour 1, 3-23.

Fryer, D. M. (1995). Benefit agency? Labour market disadvantage, deprivation and mental health. The Psychologist, June, 265-272.

Fryer, D. \& Payne, R. (1984). Proactive behaviour in unemployment; findings and implications. Leisure Studies, 3, $273-295$.

Goldberg, D. P. (1972). The detection of psychological illness by questionnaire. London: Oxford University Press.

Haworth, J. T. (1997). Work, leisure and well-being. New York: Routledge.

Jahoda, M. (1982). Employment and Unemployment: A social Psychological Analysis. Cambridge: Cambridge University Press.

Jahoda, M. (1984). Social institutions and human needs: A comment on Fryer and Payne. Leisure Studies, 3, 297-299.

Muller, J., Creed, P. A., Waters, L. \& Machin, M. A. (2000). A new scale to measure the latent functions of employment. International Journal of Psychology, 35(3-4), 266.

Murphy, P. E., Ciarrochi. J. W., Piedmont, R. L., Chesterton, S., Peyrot, M., \& Fitchett, G. (2000). The relationship of religious belief and practices, depression and hopelessness in persons with clinical depression. Journal of Consulting and Clinical Psychology, 68, 1102-1106. 
Piedmont, P. L. (1999). Does spirituality represent the sixth factor of personality? Spiritual transcendence and the five factor model. Journal of Personality, 67, 6, 986-1013.

Slater, W., Hall, T., \& Edwards, K. (2001) Measuring religion and spirituality: Where are we and where are we going? Journal of Psychology and Theology, 29,1, 4 - 14.

Tabachnick, B. G., \& Fidell, L.S. (1996). Using Mulitvariate Statistics $3^{\text {rd }}$ Ed. California: Harper Collins.

Waters L. \& Muller, J. (2003). Money or time? Comparing the effects of time structure and financial deprivation on the psychological distress of unemployed adults. Australian Journal of Psychology, 55(2), 166-175.

Weber, M. (1924). Legitimate Authority and Bureaucracy. In Pugh, D. S. (Ed.). Organization Theory $4^{\text {th }} E d$. Australia: Penguin Books.

Wood, J., Wallace, J., Zeffane, R. M., Schermerhorn, J. R., Hunt, J. G. \& Osborn, R. N. (1998). Organizational Behaviour: An Asia-Pacific Perspective. Brisbane: Wiley. Council for Educational Research. Copyright 2004 Australian Council for Educational Research. 